\title{
Fauna flebotomínica e soroprevalência para leishmaniose visceral canina em área urbana na região Centro-Oeste do Brasil
}

[Phlebotomine fauna and seroprevalence for canine visceral leishmaniasis in urban area from Central-West region of Brazil]

\author{
J.A. Menegatti ${ }^{1,4}$, G.J. Oliveira Júnior ${ }^{2}$, L.C.F. Silva ${ }^{3}$, A. Oliveira ${ }^{4}$, D.L.C. Bica ${ }^{4}$, \\ P.V.B.A. Santos ${ }^{4}$, L.F.C. Cunha Filho ${ }^{5}$, M. Lunardi ${ }^{6, *}$ \\ ${ }^{1}$ Secretaria de Estado de Saúde de Mato Grosso - Cuiabá, MT \\ ${ }^{2}$ Universidade Federal de Mato Grosso - Cuiabá, MT \\ ${ }^{3}$ Aluno de pós-graduação - Faculdade de Medicina - Universidade Federal de Mato Grosso - Cuiabá, MT \\ ${ }^{4}$ Aluno de graduação - Laboratório de Microbiologia Veterinária - Universidade de Cuiabá - Cuiabá, MT \\ ${ }^{5}$ Universidade Norte do Paraná - Arapongas, PR \\ ${ }^{6}$ Laboratório de Microbiologia Veterinária - Universidade de Cuiabá - Cuiabá, MT
}

\begin{abstract}
RESUMO
A leishmaniose visceral americana (LVA) é uma zoonose de transmissão vetorial na qual o cão tem papel importante na epidemiologia da doença. No Brasil, a elevada prevalência da infecção em cães está diretamente correlacionada com o aumento no risco de ocorrência de casos de LVA. O objetivo deste estudo foi investigar a fauna flebotomínica e verificar a soroprevalência da leishmaniose visceral canina (LVC) na localidade Pedra 90, no município de Cuiabá. Para o levantamento entomológico, armadilhas CDC foram utilizadas de agosto de 2014 a julho de 2015. Na avaliação sorológica dos cães, o teste imunocromatográfico DPP LVC foi utilizado para a triagem das amostras, enquanto o ensaio imunoenzimático (EIE) para o diagnóstico da LVC (Bio-Manguinhos) foi empregado como teste confirmatório. O trabalho vem acrescentar à fauna flebotomínica do município de Cuiabá as espécies Lu. andersoni, Lu. braziliensis, Lu. bourrouli e Lu. scaffi, não registradas em publicações anteriores. Além disso, entre as espécies de flebotomíneos com importância médica, $L u$. cruzi, Lu. flaviscutellata e $L u$. whitmani foram capturadas. No inquérito canino, a prevalência de LVC observada na localidade Pedra 90 foi de $1,14 \%$, indicando que a região pode ser considerada como área de transmissão.
\end{abstract}

Palavras-chave: cão, Leishmania, ELISA, sorologia, entomologia

\begin{abstract}
American visceral leishmaniasis (AVL) is a vector-borne zoonosis in which the dog has an important role in the epidemiology of the disease. In Brazil, a high prevalence of canine infection is directly correlated with an increased risk of occurrence of AVL. The aim of this study was to investigate the phlebotomine fauna and seroprevalence of canine visceral leishmaniasis in Pedra 90 region of Cuiabá municipality. For the entomological survey, CDC traps were used from August 2014 to July 2015. In the serological evaluation of dogs, the immunochromatographic test DPP LVC was employed for screening the samples while enzyme-linked immunosorbent assay (Bio-Manguinhos) was used as a confirmatory assay. The previously unreported phlebotomine species Lu. andersoni, Lu. braziliensis, Lu. bourrouli, and Lu. scaffi were added to the phlebotomine fauna of Cuiabá. In addition, the medically important phlebotomine species $\mathrm{Lu}$. cruzi, Lu. flaviscutellata, and Lu. whitmani were identified. The canine survey revealed the prevalence of $1.14 \%$ for canine visceral leishmaniasis in the Pedra 90 region, the region being considered a transmission area.
\end{abstract}

Keywords: dog, Leishmania, ELISA, serology, entomology

Recebido em 10 de junho de 2019

Aceito em 29 de janeiro de 2020

*Autor para correspondência (corresponding author)

E-mail: michelelunardi@gmail.com 


\section{INTRODUÇÃO}

A leishmaniose visceral americana (LVA) é a forma mais severa das leishmanioses, sendo determinada na América Latina pela Leishmania (Leishmania) infantum chagasi (Lainson e Shaw, 2007) (Brasil, 2006). A LVA é transmitida por flebotomíneos infectados pela $L$. infantum, sendo, no Brasil, Lutzomyia longipalpis (Lutz \& Neiva, 1912) e Lutzomyia cruzi (Brasil, 2006) as principais espécies vetoras envolvidas na transmissão, ambas presentes no estado de Mato Grosso (Missawa e Maciel, 2007). Inicialmente, a LVA era restrita ao ambiente rural, no entanto sua incidência no meio urbano foi acompanhada pela colonização e adaptação dos flebotomíneos a ambientes domésticos ou antrópicos (Marcondes e Day, 2019).

O cão doméstico tem sido considerado o principal reservatório urbano da $L$. infantum. No Brasil, a elevada prevalência da infecção em cães está diretamente correlacionada com o aumento no risco de ocorrência de casos de LVA (Brasil, 2006). A determinação da prevalência da infecção em populações caninas de diversas regiões geográficas é dificultada por uma série de fatores, entre eles o caráter comum da ocorrência de infecções subclínicas ou assintomáticas nesses animais (Miró et al., 2008).

Diante da dificuldade no controle da LVA, existe a necessidade de se definirem as áreas de transmissão ou de risco para a infecção, visando à implementação de estratégias de vigilância e controle da doença, compreendendo principalmente a vigilância entomológica e de casos humanos e caninos (Brasil, 2006). Conforme dados verificados no Sistema de Informação de Agravos e Notificação, da Secretária de Estado de Saúde de Mato Grosso (Sinan/SES-MT), 11 casos autóctones de LVA foram notificados em Cuiabá, nos anos de 2009 a 2013, com ocorrência de três óbitos no referido período (Mato Grosso, 2015). Como a região Pedra 90 concentrou a maioria dos casos humanos de LVA desse período, o objetivo deste estudo compreendeu investigar a fauna flebotomínica, a ocorrência das principais espécies vetoras das leishmanioses nessa localidade, assim como verificar a soroprevalência de leishmaniose visceral canina (LVC) na população canina da área, para confirmar a área em questão como de transmissão para essa enfermidade.

\section{MATERIAL E MÉTODOS}

Este estudo foi submetido à Comissão de Ética no Uso de Animais da Universidade de Cuiabá (CEUA/UNIC) e aprovado sob o número 014/2014. A área de estudo compreendeu a região Pedra 90, localizada no limite do perímetro urbano do distrito sul do município de Cuiabá (Fig. 1).

Os levantamentos entomológicos foram realizados utilizando-se 10 armadilhas luminosas tipo Centers for Disease Control (CDC), instaladas ao entardecer, no peridomicílio, durante três noites consecutivas mensalmente, à altura aproximada de 1,5 a 1,8 metros do solo, e retiradas ao amanhecer (Brasil, 2006), de agosto de 2014 a julho de 2015. Os locais de instalação foram georreferenciados com utilização de Sistema de Posicionamento Global (GPS).

Para instalação das armadilhas CDC, 10 domicílios sugestivos para presença de flebotomíneos (com abundância de plantas, presença de animais domésticos e/ou de criação) foram selecionados. Destes, cinco pontos de amostragem de flebotomíneos, designados de um a cinco, apresentavam área peridomiciliar ampla, com manutenção de parte da cobertura vegetal nativa do cerrado (chácaras), enquanto os outros cinco pontos, designados de seis a 10 , eram caracterizados por área peridomicilar restrita (residências) (Fig. 2).

Na instalação das armadilhas CDC, foi preenchida a ficha de campo com as seguintes informações: coordenadas geográficas, endereço de instalação, local de instalação (tipo de abrigo) e variáveis ambientais (umidade relativa do ar, temperatura, vento, fase lunar). Os dados meteorológicos foram obtidos junto ao Instituto Nacional de Meteorologia (Inmet), $9^{\circ}$ Distrito, Cuiabá. 


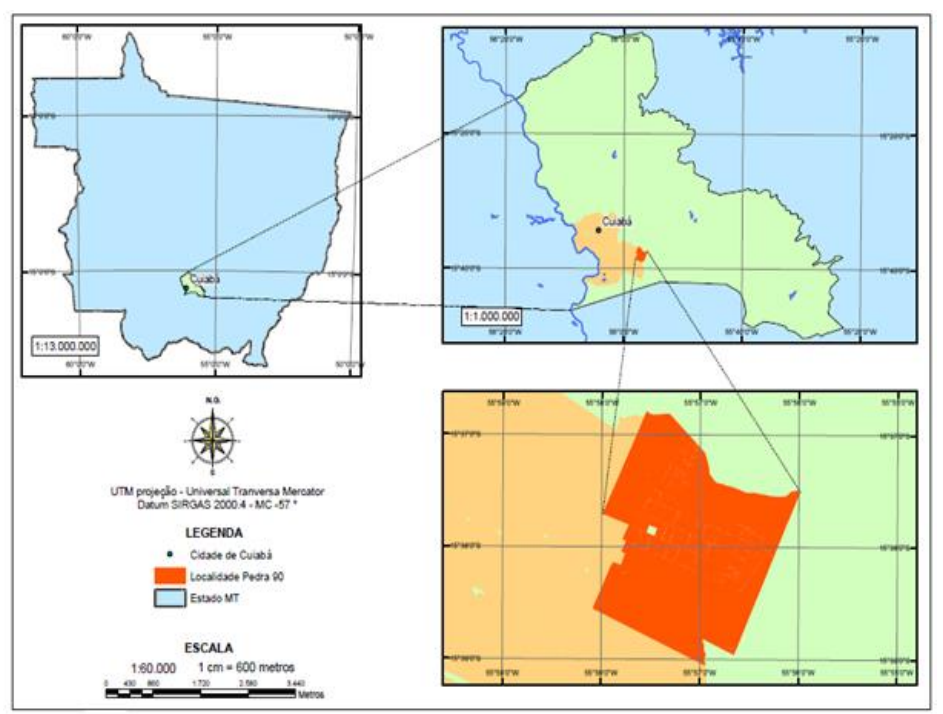

Figura 1. Localização da região Pedra 90, em área limítrofe do perímetro urbano, no distrito sul do município de Cuiabá, Mato Grosso.

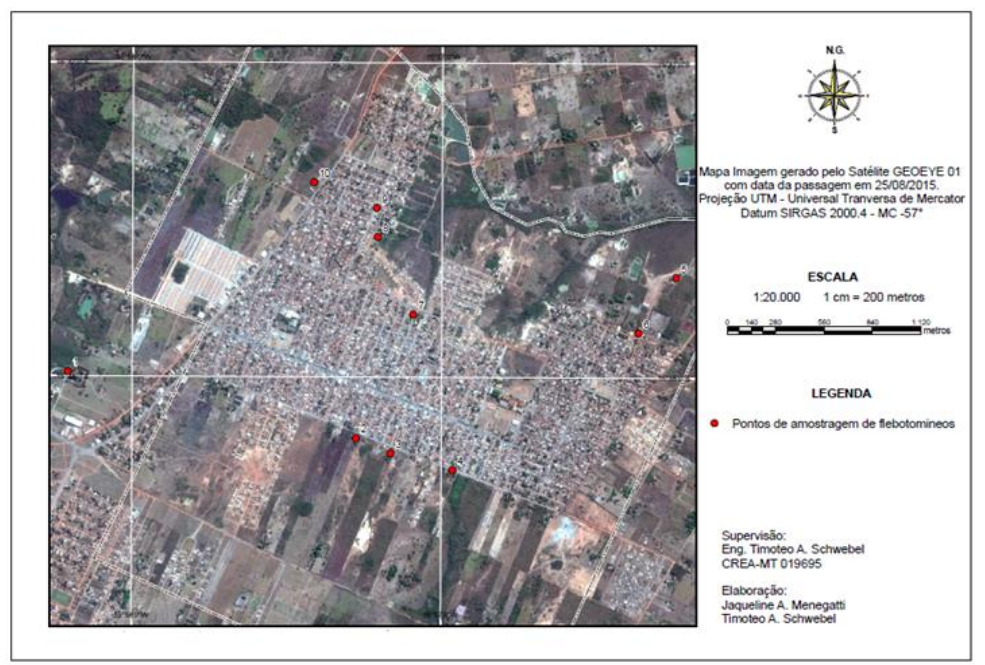

Figura 2. Pontos de amostragem de flebotomíneos, selecionados no estudo para a instalação de armadilhas luminosas CDC na localidade Pedra 90, no município de Cuiabá, Mato Grosso, no período de agosto de 2014 a julho de 2015.

Os insetos capturados foram transportados ao Laboratório de Entomologia, da Secretaria de Estado de Saúde de Mato Grosso (SES-MT), eutanasiados por congelamento a $-20^{\circ} \mathrm{C}$ e triados em microscópio estereoscópio. Somente os flebotomíneos foram submetidos à clarificação e identificados ao microscópio óptico, empregandose a chave de identificação descrita por Young e Ducan (1994).

Para o levantamento sorológico nos cães da região Pedra 90, o tamanho da amostra canina foi definido de acordo com o preconizado pelo
Ministério da Saúde, cuja estimativa varia de 10 a $20 \%$ da população humana da localidade. Portanto, uma vez que a população canina estimada para essa área foi de 4.426 cães e prevalência de $30 \%$, 350 cães pertencentes a ambos os gêneros e com idade igual ou superior a seis meses, foram avaliados neste estudo (Brasil, 2006). Para o cálculo, foi utilizado nível de significância de $5 \%$ e intervalo de confiança de 95\% no programa Epi Info 7.

As coletas de soro sanguíneo canino ocorreram de janeiro a julho de 2015. O sangue de todos os cães 
dos domicílios onde foram instaladas as armadilhas para flebotomíneos foi coletado, assim como das residências de quarteirões na região Pedra 90, sorteados aleatoriamente, empregandose a tabela de números aleatórios (Brasil, 2006). No momento da coleta, questionários com informações contendo dados dos animais foram preenchidos. As alíquotas de soro obtidas foram mantidas em freezer a $-20^{\circ} \mathrm{C}$, até a realização dos testes.

Seguindo o critério estabelecido pelo Ministério da Saúde, para o diagnóstico sorológico de LVC, o teste rápido imunocromatográfico qualitativo DPP LVC (Bio-Manguinhos, Fiocruz, Brasil) foi empregado na triagem das amostras, conforme as instruções do fabricante. Esse teste contém proteínas recombinantes $\mathrm{k} 28$ de Leishmania infantum. As amostras reagentes foram encaminhadas ao Centro de Controle de Zoonoses (CCZ) de Cuiabá e posteriormente enviadas ao Laboratório Central de Saúde Pública do Estado de Mato Grosso, para confirmação através do ensaio imunoenzimático (EIE) para diagnóstico da leishmaniose visceral canina, o qual contém antígenos solúveis e purificados de promastigotas de Leishmania major like obtidos a partir de cultura in vitro, conforme instruções do fabricante (Bio-Manguinhos, Fiocruz, Brasil).

Por se tratar de estudo transversal, utilizou-se o cálculo da prevalência para os animais sororreagentes para LVC e razão de prevalência para a medida de associação entre as variáveis estudadas. A análise dos dados foi realizada por meio do teste qui-quadrado, utilizando-se o programa BioEstat 5.0.

\section{RESULTADOS}

Nos levantamentos da fauna flebotomínica, após 12 meses, foram capturados 177 espécimes de flebotomíneos no peridomicílio das habitações avaliadas, sendo 43,5\% fêmeas e 56,5\% machos. A fauna flebotomínica foi composta por dois gêneros, Brumptomyia e Lutzomyia, com alta diversidade de espécies (Tab. 1).

Tabela 1. Frequência absoluta de flebotomíneos capturados, conforme espécie identificada e sexo, na região Pedra 90 do município de Cuiabá, Mato Grosso, entre agosto de 2014 e julho de 2015

\begin{tabular}{lllllll}
\hline & Macho & $\%$ & Fêmea & $\%$ & Total & $\%$ \\
\hline Brumptomyia sp. & 1 & 1,04 & - & - & 1 & 0,56 \\
Brumptomyia brumpti & 9 & 9,38 & 10 & 12,34 & 19 & 10,73 \\
Lutzomyia sp. & 1 & 1,04 & - & - & 1 & 0,56 \\
Lutzomyia acanthopharynx & 1 & 1,04 & 8 & 9,88 & 9 & 5,08 \\
Lutzomyia andersoni & 2 & 2,08 & - & - & 2 & 1,30 \\
Lutzomyia antunesi & 2 & 2,08 & - & - & 2 & 1,30 \\
Lutzomyia aragaoi & 1 & 1,04 & - & - & 1 & 0,56 \\
Lutzomyia braziliensis & - & - & 1 & 1,23 & 1 & 0,56 \\
Lutzomyia bourrouli & - & - & 1 & 1,23 & 1 & 0,56 \\
Lutzomyia carmelinoi & - & - & 1 & 1,23 & 1 & 0,56 \\
Lutzomyia cruzi & 2 & 2,08 & 2 & 2,47 & 4 & 2,26 \\
Lutzomyia evandroi & 14 & 14,58 & 17 & 2,98 & 31 & 17,51 \\
Lutzomyia flaviscutellata & 2 & 2,08 & 6 & 7,40 & 8 & 4,52 \\
Lutzomyia hermanlenti & 2 & 2,08 & 2 & 2,47 & 4 & 2,26 \\
Lutzomyia lenti & 9 & 9,38 & 5 & 6,17 & 14 & 7,90 \\
Lutzomyia lutziana & 2 & 2,08 & - & - & 2 & 1,30 \\
Lutzomyia punctigeniculata & 1 & 1,04 & 2 & 2,47 & 3 & 1,69 \\
Lutzomyia shannoni & - & - & 2 & 2,47 & 2 & 1,30 \\
Lutzomyia sordellii & 1 & 1,04 & 1 & 1,23 & 2 & 1,30 \\
Lutzomyia scaffi & - & - & 2 & 2,47 & 2 & 1,30 \\
Lutzomyia teratodes & 1 & 1,04 & - & - & 1 & 0,56 \\
Lutzomyia whitmani & 42 & 43,75 & 16 & 19,75 & 58 & 32,76 \\
Total & 96 & & 81 & & 177 & \\
\hline
\end{tabular}

Nos pontos de coleta 1, 2, 3 e 4, instalados em chácaras, e no ponto 10, instalado em uma residência, foram verificados os maiores números absolutos de espécies de flebotomíneos. A espécie de flebotomíneo capturada em maior abundância, durante o período pesquisado, foi Lu. whitmani, a qual foi identificada nos pontos de coleta $1,2,3$, 4, 5 e 7 . A presença de Lu. flaviscutellata também 
foi demonstrada nos pontos de coleta 1,4 e 6 , sendo ambas vetores da leishmaniose tegumentar americana (LTA). Entretanto, foi registrada a presença de $L u$. cruzi, vetor da LVA, nos pontos de coletas 2, 3 e 10 da região Pedra 90.

Durante os 12 meses de levantamentos entomológicos, a maior densidade de flebotomíneos capturados foi observada em outubro de 2014, enquanto em 2015 a maior abundância foi verificada em abril. As variáveis ambientais precipitação pluviométrica, temperatura e umidade relativa do ar, cedidas pelo Inmet $9^{\circ}$ Distrito, Cuiabá, indicaram, nos meses de maior abundância de flebotomíneos, precipitação média de $3,0 \mathrm{~mm}$ por $\mathrm{m}^{2}$ em outubro de 2014 , e $37,8 \mathrm{~mm}$ por $\mathrm{m}^{2}$ em abril de 2015 . A temperatura média registrada foi de $32,9^{\circ} \mathrm{C}$, em outubro de 2014 , e de $27,61^{\circ} \mathrm{C}$, em abril de 2015 .

Neste estudo, entre os cães avaliados, somente os animais cujo soro foi reagente em ambos os testes sorológicos empregados (teste imunocromatográfico DPP e ELISA) foram definidos como infectados pela $L$. infantum. Portanto, a prevalência de LVC entre os cães avaliados na localidade Pedra 90 foi de 1,14\% (4/350). Nos cães fêmeas, a prevalência de LVC registrada foi 2,68 vezes a prevalência observada nos cães machos. Quanto às variáveis idade e cidade de origem, não foi verificada diferença na ocorrência da infecção. Com relação à raça, todos os cães sororreagentes eram sem raça definida (SRD).

$\mathrm{Na}$ análise das variáveis de risco para LVC, em relação aos casos de LVC diagnosticados na área de estudo, foi observado que $75 \%$ dos animais sororreagentes, segundo informações dos proprietários, não tinham acesso à rua, não residiam em domicílios com presença de galinheiro, curral ou plantas no quintal. Contudo, a presença de insetos foi relatada pelos proprietários em $75 \%$ das moradias contendo cães infectados, os quais, em sua totalidade (100\%), viviam exclusivamente no peridomicílio, sem acesso ao interior das habitações. Além disso, $75 \%$ dos cães com LVC conviviam há mais de um ano com a família, sendo a razão de prevalência de LVC em cães infectados que estavam há menos de um ano convivendo com a mesma família 1,20 vez a de cães que conviviam com a mesma família há mais de um ano. Para o cão cujo proprietário informou possuir informações sobre a zoonose, a razão de prevalência foi 1,52 vez a de cães cujos proprietários informaram desconhecer a doença (Tab. 2).

\section{DISCUSSÃO}

Na região Pedra 90 de Cuiabá, de agosto de 2014 a julho de 2015, os flebotomíneos foram mais abundantes na maioria das chácaras avaliadas, sendo capturados 128 espécimes nesses ambientes. Nesses pontos de coleta, havia o predomínio do ecótopo cerrado, com características favoráveis à proliferação de flebotomíneos, devido à presença de animais sinantrópicos, silvestres, domésticos e de criação, principalmente aves. Esse achado está de acordo com o relatado em estudos anteriores da fauna flebotomínea dos municípios de Jaciara e Várzea Grande, em Mato Grosso, os quais apontaram a preferência alimentar de vetores das leishmanioses por sangue de aves (Missawa et al., 2008; Brito et al., 2014). Além disso, estudo que avaliou a distribuição geográfica de espécies de flebotomíneos na região Centro-Oeste do Brasil indicou o bioma cerrado como climaticamente mais adequado para a manutenção dos flebotomíneos (Almeida et al., 2015).

Neste estudo, apesar da baixa frequência absoluta de flebotomíneos em relação ao número total de espécimes capturados, elevada diversidade de flebotomíneos, compreendendo 20 diferentes espécies pertencentes ao gênero Lutzomyia, foi observada na região Pedra 90, pertencente à zona urbana de Cuiabá. Elevada diversidade em espécies de flebotomíneos capturados também foi descrita em investigação no município de Pontal do Araguaia (MT), onde 14 espécies diferentes foram identificadas em área urbana do município, indicando um potencial sinantrópico de espécies vetoras das leishmanioses (Amaral et al., 2011). Em estudo entomológico conduzido em quatro bairros de Cuiabá, entre novembro de 2007 e outubro de 2008, com casos confirmados de LVA ou LVC, também foi verificada baixa densidade de flebotomíneos capturados, no entanto a diversidade de espécies observada foi inferior à demonstrada neste estudo, envolvendo apenas nove diferentes espécies (Freitas, 2010). 
Tabela 2. Análise das variáveis de risco para leishmaniose visceral canina, em população canina da região Pedra 90, distrito sul do município de Cuiabá, Mato Grosso, de janeiro a julho de 2015

\begin{tabular}{|c|c|c|c|c|c|c|c|}
\hline \multirow[t]{2}{*}{ Variáveis } & \multicolumn{2}{|r|}{$\begin{array}{c}\text { Positivo } \\
(\mathrm{n}=4)\end{array}$} & \multicolumn{2}{|c|}{$\begin{array}{l}\text { Negativo } \\
(\mathrm{n}=346)\end{array}$} & \multirow[t]{2}{*}{ Prevalência } & \multirow{2}{*}{$\begin{array}{c}\text { Razão de } \\
\text { Prevalência }\end{array}$} & \multirow[t]{2}{*}{ P-valor } \\
\hline & $\mathrm{n}$ & $\%$ & $\mathrm{n}$ & $\%$ & & & \\
\hline \multicolumn{8}{|l|}{ Idade (anos) } \\
\hline$<1$ & 1 & $25,00 \%$ & 64 & $18,50 \%$ & 0,02 & 1,00 & \multirow{5}{*}{0,132} \\
\hline 1 a 3 & 1 & $25,00 \%$ & 145 & $41,90 \%$ & 0,01 & 0,45 & \\
\hline 4 a 6 & 1 & $25,00 \%$ & 79 & $22,80 \%$ & 0,01 & 0,81 & \\
\hline$>6$ & 0 & - & 48 & $13,90 \%$ & 0,00 & - & \\
\hline Não soube informar & 1 & $25,00 \%$ & 10 & $2,90 \%$ & 0,09 & 5,91 & \\
\hline \multicolumn{8}{|l|}{ Cidade de origem } \\
\hline Cuiabá & 2 & $50,00 \%$ & 312 & $90.20 \%$ & 0,01 & 0,11 & \multirow[t]{2}{*}{0,071} \\
\hline Outros & 2 & $50,00 \%$ & 34 & $9,80 \%$ & 0,06 & 1,00 & \\
\hline \multicolumn{8}{|l|}{ Acesso à rua } \\
\hline Sim & 1 & $25,00 \%$ & 128 & $37,00 \%$ & 0,01 & 0,57 & \multirow[t]{2}{*}{0,978} \\
\hline Não & 3 & $75,00 \%$ & 218 & $63,00 \%$ & 0,01 & 1,00 & \\
\hline \multicolumn{8}{|c|}{$\begin{array}{l}\text { Presença de galinheiro, } \\
\text { curral e plantas }\end{array}$} \\
\hline Sim & 1 & $25,00 \%$ & 99 & $28,60 \%$ & 0,01 & 0,83 & \multirow{2}{*}{0,691} \\
\hline Não & 3 & $75,00 \%$ & 247 & $71,40 \%$ & 0,01 & 1.00 & \\
\hline \multicolumn{8}{|l|}{$\begin{array}{l}\text { Presença de } \\
\text { insetos }\end{array}$} \\
\hline Sim & 3 & $75,00 \%$ & 228 & $65.90 \%$ & 0,01 & 1,55 & \multirow[t]{2}{*}{0,702} \\
\hline Não & 1 & $25,00 \%$ & 118 & $34.10 \%$ & 0,01 & 1,00 & \\
\hline \multicolumn{8}{|l|}{$\begin{array}{l}\text { Tempo com a } \\
\text { família }\end{array}$} \\
\hline Menos de 1 ano & 1 & $25,00 \%$ & 75 & $21,70 \%$ & 0,01 & 1,20 & \multirow[t]{2}{*}{0,653} \\
\hline Mais de 1 ano & 3 & $75,00 \%$ & 271 & $78,30 \%$ & 0,01 & 1,00 & \\
\hline \multicolumn{8}{|l|}{$\begin{array}{l}\text { Proprietário conhece } \\
\text { a doença }\end{array}$} \\
\hline Sim & 1 & $25,00 \%$ & 62 & $17,90 \%$ & 0,02 & 1,52 & \multirow[t]{2}{*}{0,773} \\
\hline Não & 3 & $75,00 \%$ & 284 & $82,10 \%$ & 0,01 & 1,00 & \\
\hline
\end{tabular}

O presente estudo contribuiu para a identificação das espécies $L u$. andersoni, Lu. braziliensis, $L u$. bourrouli e Lu. scaffi em Cuiabá, sem registros anteriores de ocorrência. Entretanto, a ocorrência dessas espécies em outros municípios de Mato Grosso já foi documentada (Missawa e Maciel, 2007; Mestre et al., 2011; Thies et al., 2013; Campelo Júnior et al., 2014). Portanto, a fauna flebotomínica do município passa a ser composta por 31 espécies distintas do gênero Lutzomyia. Levantamentos entomológicos anteriores descreveram 27 diferentes espécies de flebotomíneos no município de Cuiabá (Freitas, 2010; Mestre et al., 2011; Campelo Júnior et al., 2014).

Entre as espécies de flebotomíneos com importância médica, Lu. cruzi, Lu. flaviscutellata e $L u$. whitmani foram capturadas. A espécie $L u$. cruzi foi identificada naturalmente infectada com Leishmania (Leishmania) infantum chagasi em algumas regiões endêmicas do país, tais como Corumbá (Mato Grosso do Sul) e Jaciara (Mato Grosso), tendo reconhecido o seu papel na epidemiologia da LVA (Pita-Pereira et al., 2008; Brito et al., 2014). Em estudo anterior, Missawa et al. (2011) correlacionaram a presença de $L u$. cruzi com a ocorrência de casos humanos de leishmaniose visceral em Jaciara, Mato Grosso.
Portanto, apesar de a espécie Lu. longipalpis não ter sido detectada entre as espécies de flebotomíneos capturadas nesta investigação, a detecção da espécie $L u$. cruzi justifica a confirmação da ocorrência de casos humanos de LVA nessa região anteriormente ao período deste estudo, assim como sugere essa espécie como vetora para as infecções caninas evidenciadas por meio do diagnóstico sorológico nessa localidade. Além disso, em estudo que avaliou a fauna flebotomínea do distrito norte de Cuiabá, nos anos de 2008 e 2009, a espécie vetora Lu. longipalpis também não foi capturada em dois dos cinco bairros avaliados (Mestre et al., 2011). De maneira similar, em pesquisa entomológica de 2007-2008, conduzida em bairros de Cuiabá com casos de LVA e LVC confirmados, apenas um exemplar fêmea, pertencente ao complexo longipalpis, no qual estão inseridas as espécies Lu. longipalpis e Lu. cruzi, foi capturado ao longo do período do estudo, indicando a possibilidade de participação de outras espécies de flebotomíneos na cadeia de transmissão da $L$. infantum nessa localidade (Freitas, 2010).

Em Jacaré, distrito de Niterói (Rio de Janeiro), em levantamento entomológico realizado de maneira semelhante ao deste estudo, o principal vetor da LVA, Lu. longipalpis, também não foi capturado, 
apesar da detecção de LVC por ensaios sorológicos (Oliveira et al., 2015). Esses autores levantaram suspeitas sobre o envolvimento de outros mecanismos de transmissão da doença na área, como a participação de outras espécies de flebotomíneos, ou até mesmo de carrapatos. Dessa maneira, pode-se inferir a ocorrência de situação similar em outras regiões do país, havendo a necessidade de investigação da capacidade vetorial de outras espécies de flebotomíneos capturadas em áreas de transmissão da doença, principalmente com baixa densidade dos vetores já incriminados na transmissão da LVA, assim como a verificação da participação de outros reservatórios além do cão doméstico em tais localidades. Em estudo conduzido em Rondonópolis (MT), área de transmissão intensa de LVA, a avaliação de animais sinantrópicos capturados em bairros com casos confirmados de LVA e LVC demonstrou a infecção natural de marsupiais da espécie Didelphis albiventris e roedores Necromys lasiurus e Rattus rattus pela Leishmania (L.) infantum chagasi, por meio da técnica de PCRRFLP (Freitas, 2010).

As espécies vetoras da LTA Lu. flaviscutellata e $\mathrm{Lu}$. whitmani também foram capturadas na região Pedra 90, tendo a última espécie, considerada o principal vetor de LTA no Brasil, ocorrido em maior abundância, principalmente nos pontos de amostragem caracterizados como chácaras, onde foi observada a manutenção de parte da cobertura vegetal nativa do cerrado (Brasil, 2017). Esses achados estão de acordo com os descritos anteriormente, que observaram ampla distribuição dessa espécie vetora na região Centro-Oeste (Almeida et al., 2015).

A densidade de flebotomíneos foi maior nos meses de outubro de 2014 e abril de 2015 , com temperaturas médias de $32,9^{\circ} \mathrm{C}$ e $27,61^{\circ} \mathrm{C}$, e médias da umidade relativa do ar de $78,83 \%$ e $68 \%$, respectivamente, não sendo observada influência significativa da temperatura e da umidade relativa do ar na abundância de flebotomíneos capturados, uma vez que, em meses com variáveis ambientais semelhantes, a frequência absoluta de flebotomíneos coletados apresentou variações. A precipitação, de acordo com o início e o final da estação de chuvas, pode ter contribuído para o aumento da densidade de flebotomíneos nesses meses. Tal observação corrobora os achados descritos em trabalho anteriormente realizado em outras localidades de Cuiabá, no qual maior abundância de flebotomíneos também foi verificada nesses meses (Mestre et al., 2011).

Apesar da reconhecida influência que os diversos fatores climáticos e ambientais exercem na densidade e abundância de flebotomíneos, diversos estudos falharam em demonstrar essa correlação (Missawa et al., 2007; Mestre et al., 2011; Oliveira et al., 2016). Esse fato aponta para a provável interferência de fatores não climáticos, como epidemiológicos, demográficos e socioeconômicos, na população de vetores relacionados com a transmissão de doenças (Parham et al., 2015; Oliveira et al., 2016).

O inquérito canino amostral anual é recomendado pelo Ministério da Saúde, para avaliar as taxas de prevalência em cada setor, identificando setores prioritários (Brasil, 2006). A soropositividade de $1,14 \%$ para LVC é um importante registro da existência de animais sororreagentes na localidade Pedra 90, confirmando as informações de Blatt (2009), que relatou, em estudos anteriores, soropositividade canina $\leq 2 \%$ no distrito Sul de Cuiabá. Nesse distrito, foram registrados, no Sinan-MT, casos humanos de LVA no período que antecedeu o início dos estudos na região Pedra 90 (Mato Grosso, 2015). Entre os cães avaliados, a maioria era natural da localidade e convivia há mais de um ano com a família. Porém, dois dos animais diagnosticados com LVC eram oriundos dos municípios de Campo Verde (MT), área endêmica para LVC, e Jaciara (MT), área endêmica para LVC e LVA, não sendo possível determinar com precisão o local de ocorrência da infecção (Brito et al., 2014).

Todos os animais sororreagentes para LVC neste estudo não apresentavam sinais clínicos característicos da doença no momento da coleta de sangue. O diagnóstico de cães infectados, porém assintomáticos para a LVC, é considerado um desafio, pois sabe-se que o percentual de soropositividade é maior em animais com clínica aparente do que nos infectados subclinicamente, sendo, portanto, difícil estimar a prevalência real desses animais em um população (Miró et al., 2008). A importância desse achado se deve também ao fato de os animais infectados subclinicamente poderem constituir fonte de infecção para os flebotomíneos vetores da doença (Santos et al., 2010).

Entre os animais avaliados, a minoria residia em ambientes propícios ao desenvolvimento do vetor, ou seja, próximos à mata, terrenos baldios, corpos d'agua, criações de aves domésticas, sendo poucas as habitações que possuíam plantas no quintal. Esta observação poderia justificar a baixa ocorrência de LVC na região, uma vez que, apesar da carência de infraestrutura da localidade, os fatores de risco favoráveis à proliferação dos vetores desta zoonose estavam ausentes na maioria dos domicílios avaliados. 
Nesta investigação, segundo informações dos proprietários, $75 \%$ dos animais sororreagentes conviviam com insetos no quintal. Apesar desses relatos, não foi possível concluir que esses insetos fossem flebotomíneos. A densidade vetorial também é considerada fator de risco para LVC, pois, segundo Monteiro et al. (2005), a presença elevada do vetor e de cães com LVC constitui um grave problema de saúde pública. No entanto, a maioria dos cães sororreagentes não tinha acesso à rua, o que pode indicar que foram infectados no quintal.

A abundância limitada observada na detecção das principais espécies de flebotomíneos vetores da LVA na região Pedra 90, em Cuiabá, assim como a baixa soroprevalência para LVC verificada em cães residentes na área avaliada apontam para uma provável redução do potencial de ocorrência de casos de LVA afetando a população humana da localidade. No entanto, sabendo-se que os métodos sorológicos para diagnóstico da LVC não apresentam sensibilidade e especificidade suficientemente elevadas para identificar todos os cães infectados, deve-se ressaltar a possibilidade de ocorrência da infecção canina em percentual superior ao relatado neste trabalho para essa região (Courtenay et al., 2002; Coura-Vital et al., 2014). Além disso, deve-se considerar que diversos fatores, tais como migração de humanos ou cães infectados para a região, maior disponibilização de substrato orgânico e/ou condições climáticas favoráveis para a reprodução dos flebotomíneos vetores, bem como comprometimento das condições de infraestrutura do local, poderiam reverter a situação epidemiológica relatada. Esses fatos justificam a necessidade de realização de monitoramentos entomológicos periódicos nessa área de transmissão da LVA, além de futura investigação para verificar a possível participação de animais sinantrópicos na cadeia de transmissão dessa doença na localidade Pedra 90, uma vez que ela encontra-se em região limítrofe do perímetro urbano de Cuiabá.

\section{AGRADECIMENTOS}

Ao Programa de Pós-Graduação em Biociência Animal, da Universidade de Cuiabá (UNIC), pelo apoio financeiro; ao apoio dos profissionais do Laboratório de Entomologia, SES-MT e do Centro de Controle de Zoonoses de Cuiabá; aos técnicos do Instituto Nacional de Meteorologia do $9^{\circ}$ distrito (Inmet).

\section{REFERÊNCIAS}

ALMEIDA, O.S.; ANDRADE, A.J.A.; SCIAMARELLI, A. et al. Geographic distribution of phlebotomine sandfy species (Diptera: Psychodidae) in Central West Brazil. Mem. Inst. Oswaldo Cruz, v.110, p.551-559, 2015.

AMARAL, A.F.S.; VARJÃO, J.R.; SILVA, G.B.; ARRAIS-SILVA, W.W. Phlebotomine fauna (Diptera: Psychodidae: Phlebotominae) in a residential area and in a fragment of savanna vegetation in the municipality of Pontal do Araguaia, Mato Grosso, Brasil. Rev. Bras. Parasitol. Vet., v.20, p.165-167, 2011.

BLATT, M.C.S. Leishmaniose visceral em Cuiabá: a espacialização como instrumento para reflexão e ação. Bol. Núcleo Estudos Epidemiol., v.1, p.2-3, 2009.

BRASIL. Ministério da Saúde. Manual de vigilância e controle da leishmaniose visceral. Brasília: Ministério da Saúde, 2006. Disponível em:

<http://bvsms.saude.gov.br/bvs/publicacoes/man ual_vigilancia_controle_leishmaniose_visceral.p df $>$. Acessado em: 30 abr. 2019.

BRASIL. Ministério da Saúde. Manual de vigilância da leishmaniose tegumentar. Brasília: Ministério da Saúde, 2017. Disponível em: <http://bvsms.saude.gov.br/bvs/publicacoes/man ual_vigilancia_leishmaniose_tegumentar.pdf $>$.

Acessado em: 30 abr. 2019.

BRITO, V.N.; ALMEIDA, A.B.P.F.; NAKAZATO, L. et al. Phlebotomine fauna, natural infection rate and feeding habits of Lutzomyia cruzi in Jaciara, state of Mato Grosso, Brazil. Mem. Inst. Oswaldo Cruz, v.109, p.899904, 2014.

CAMPELO JÚNIOR, J.H.; MIYAZAKI, R.D.; RIBEIRO, A.L.M.; RODRIGUES, J.S.V. Spatial distribution and temporal variability of Phlebotominae at the Cuiabá campus of the federal university of Mato Grosso, Brazil. Rev. Patol. Trop., v.43, p.470-482, 2014.

COURA-VITAL, W.; KER, H.G.; ROATT, B.M. et al. Evaluation of change in canine diagnosis protocol adopted by the visceral leishmaniasis control program in Brazil and a new proposal for diagnosis. PloS One, v.9, p.e91009, 2014. 
COURTENAY, O.; QUINNELL, R.J.; GARCEZ, L.M. et al. Infectiousness in a cohort of brazilian dogs: why culling fails to control visceral leishmaniasis in areas of high transmission. $J$. Infect. Dis., v.186, p.1314-1320, 2002.

FREITAS, T.P.T. A ecoepidemiologia das leishmanioses: levantamento de flebotomíneos em Cuiabá e investigação quanto a participação de roedores e marsupiais em Rondonópolis, Mato Grosso. 2010. 103f. Dissertação (Mestrado em Ciências Veterinárias) - Faculdade de Agronomia e Medicina Veterinária, Universidade Federal de Mato Grosso, Cuiabá, MT.

LAINSON, R.; SHAW, J.J. New world leishmaniasis. In: COX, F.E.G.; WAKELIN, D.; GILLESPIE, S.H.; DESPOMMIER, D.D. (Eds.). Microbiology and microbial infections: parasitology. Hoboken: Wiley-Blackwell, 2007, p.313-349.

MARCONDES, M.; DAY, M.J. Current status and management of canine leishmaniasis in Latin America. Res. Vet. Sci., v.123, p.261-72, 2019.

MATO GROSSO. Secretaria de Estado de Saúde de Mato Grosso. Sistema de Informações de Agravos de Notificação (SINAN), SES/MT, Cuiabá, 2015.

MESTRE, G.L.C.; RIBEIRO, A.L.M.; MIYAZAKI, R.D. et al. Phlebotomine sand flies and canine infection in areas of human visceral leishmaniasis, Cuiabá, Mato Grosso. Rev. Bras. Parasitol. Vet., v.20, p.228-234, 2011.

MIRÓ, G.; CARDOSO, L.; PENNISI, M.G. et al. Canine leishmaniosis - new concepts and insights on an expanding zoonosis: part two. Trends Parasitol., v.24, p.371-377, 2008.

MISSAWA, N.A.; MACIEL, G.B.M.L. List of species in the genus Lutzomyia, França, 1924 (Psychodidae, Phlebotominae) from the State of Mato Grosso. Rev. Soc. Bras. Med. Trop., v.40, p.11-14, 2007.

MISSAWA, N.A.; LOROSA, E.S.; DIAS, E.S. Preferência alimentar de Lutzomyia longipalpis (Lutz \& Neiva, 1912) em área de transmissão de leishmaniose visceral em Mato Grosso. Rev. Soc. Bras. Med. Trop., v.41, p.365-368, 2008.

MISSAWA, N.A.; VELOSO, M.A.E.; MACIEL, G.B.M.L. et al. Evidência de transmissão de leishmaniose visceral por Lutzomyia cruzi no município de Jaciara, Estado de Mato Grosso, Brasil. Rev. Soc. Bras. Med. Trop., v.44, p.76-78, 2011.
MONTEIRO, E.M.; SILVA, J.C.F.; COSTA, R.T. et al. Leishmaniose visceral: estudo de flebotomíneos e infecção canina em Montes Claros, Minas Gerais. Rev. Soc. Bras. Med. Trop., v.38, p.147-152, 2005.

OLIVEIRA, A.C.; FIGUEIREDO, F.B.; SILVA, V.L. et al. Canine visceral leishmaniasis case investigation in the Jacaré region of Niterói, Rio de Janeiro, Brazil. Rev. Inst. Med. Trop. Sao Paulo, v.57, p.325-332, 2015.

OLIVEIRA, E.F.; CASARIL, A.E.; FERNANDES, W.S. et al. Monthly distribution of phlebotomine sand flies, and biotic and abiotic factors related to their abundance, in an urban area to which visceral leishmaniasis is endemic in Corumbá, Brazil. PloS One, v.11, p.e0165155, 2016.

PARHAM, P.E.; WALDOCK, J.; CHRISTOPHIDES, G.K. et al. Climate, environmental and socio-economic change: weighing up the balance in vector-borne disease transmission. Philos. Trans. R. Soc. Lond. Ser. B. Biol. Sci., v.370, p.1665, 2015.

PITA-PEREIRA, D.; CARDOSO, M.A.B.; ALVES, C.R. et al. Detection of natural infection in Lutzomyia cruzi and Lutzomyia forattinii (Diptera: Psychodidae: Phlebotominae) by Leishmania infantum chagasi in an endemic area of visceral leishmaniasis in Brazil using a PCR multiplex assay. Acta Trop., v.107, p.66-69, 2008.

SANTOS, J.M.L.; DANTAS-TORRES, F.; MATTOS, M.R.F. et al. Prevalência de anticorpos antileishmania spp em cães de Garanhuns, Agreste de Pernambuco. Rev. Soc. Bras. Med. Trop., v.43, p.41-45, 2010.

THIES, S.F.; RIBEIRO, A.L.M.; MICHALSKY, E.M. et al. Phlebotomine sandfly fauna and natural Leishmania infection rates in a rural area of Cerrado (tropical savannah) in Nova Mutum, State of Mato Grosso in Brazil. Rev. Soc. Bras. Med. Trop., v.46, p.293-298, 2013.

YOUNG, D.G.; DUNCAN, M.A. Guide to identification and geographic distribution of Lutzomyia sandflies in Mexico, the West Indies, Central and South America (Diptera: psychodidae). Logan: American Entomological Institute/Associated Publishers, 1994. 881p. 